\title{
Pengaruh Motivasi pada Penilaian Prestasi Kerja Karyawan PT. INHUTANI II Kotabaru Kalimantan Selatan
}

\author{
Kumara Efrianti \\ Dosen Fakultas Ekonomi Universitas Islam Kalimantan Muhammad Arsyad Al Banjari Banjarmasin
}

\begin{abstract}
This research discuses about motivatin of staff PT. INHUTANI II Kota Baru Kalimantan Selatan the objective of this research is to analyze the influence of physic need variables (X1), safety need (X2), social need (X3), appreciation need (X4), self actualizing need (X5). The motivation is defined as the personal condition of someone backing up the individual willing to do particular activities for reaching a purpose. In order someone being able to be motivated to do something, it need to know the weakness inside the individual that is need. From the resesarch simultaneously affect the motivation and partially take effect significant on employee performance staf PT. INHUTANI II Kota Baru kalimantan Selatan with sign 0,000 and correlation coefficient between 0,41 to 0,60 are included in the category being and accompanied by significance (sig) $0,000<0,01$.
\end{abstract}

Keywords : Motivation, Work Achivement

\section{Abstrak}

Penelitian ini mengangkat permasalahan motivasi karywan PT. INHUTANI II Kota Baru Kalimantan Selatan. Dengan tujuan melakukan analisis pengaruh variabel -variabel kebutuhan fisik (X1), kebutuhan rasa aman (X2), kebutuhan sosial (X3), kebutuhan penghargaan (X4), kebutuhan aktualisasi (X5). Motivasi didefinisikan sebagai keadaan dalam pribadi seseorang yang mendorong keinginan individu untuk melakukan kegiatan - kegiatan tertentu guna mencapai suatu tujuan. Agar seseorang terdorong untuk melakukan sesuatu, maka perlu diketahui kekurangan yang ada dalam dari individu berupa kebutuhan. Dari penelitian secara simultan berpengaruh terhadap motivasidan secara persial berpengaruh signifikan terhadap prestasi kerja karyawan PT. INHUTANI II Kota Baru kalimantan Selatandengan sign 0,000 dan koefisien korelasi antara 0,41 sd 0,60 yang termasuk dalam kategori sedang dan disertai dengan signifikasi (sig.) $0,000<0,01$.

Kata Kunci : Motivasi, Prestasi Kerja

\section{PENDAHULUAN}

Pada umunya orang-orang yang berkecimpung dalam manajemen sumber daya manusia sependapat bahwa penilaian prestasi kerja para karyawan merupakan bagian penting dari seluruh proses kekaryaan karyawan yang bersangkutan. Pentingngya penilaian prestasi kerja yang rasional dan diterapkan secara obyektif terlihat pada paling sedikit dua kepentingan, yaitu kepentingan karyawan yang bersangkutan sendiri dan kepentingan organisasi.

Bagi para karyawan, penilaian tersebut berperan sebagai umpan balik tentang berbagai hal seperti kemampuan, keletihan, kekurangan dan potensinya yang pada gilirannya bermanfaat untuk menentukan tujuan, jalur, rencana dan pengembangan kariernya.

Bagi organisasi, hasil penilaian prestasi kerja para karyawan sangat penting arti dan peranannya dalam pengambilan keputusan tentang berbagai hal, seperti identifikasi kebutuhan program pendidikan, rekrutmen, seleksi, program pengenalan, penempatan, promosi, sistem imbalan dan berbagai aspek lain dari keseluruhan proses manajemen sumber daya manusia secara efektif. Prestasi kerja adaalah suatu hasil kerja yang dicapai seseorang dalam melaksanakan tugas - tugas yang dibebankan kepadanya (Hasibuan : 1991 : 105)

Setiap perusahaan pasti mempunyai tujuan, baik yang bersifat jangka pendek maupun jangka panjang. Tercapainya suatu tujuan bukanlah merupakan suatu hal yang dapat terjadi secara kebetulan atau dengan begitu saja tetapi melalui suatu proses.

Melihat akan petingnya pengaruh motivasi terhadap prestasi kerja karyawan, maka sudah sepatutnya motivasi diberikan kepada setiap organisasi, baik oraganisasi swasta maupun organisasi pemerintah. Sehingga pemberian motivasi adalah mutlak diperlukan untuk mendorong karyawan dalam berprestasi yang pada akhirnya akan mempelancar tugas - tugas perusahaan.

Faktor tenaga kerja tidak dapat diabaikan, bahkan merupakan slah satu faktor kunci, sebab kesalahan dan kekeliruan yang terjadi dapat menyebabkan hambata - hambatan yang serius, bahkan dapat menyebabkan karyawan dapat dapat bekerja dengan giat, karena dengan motivasi akan menetukan prestasi seseorang. Hal ini sependapat dengan motivasi akan menentukan prestasi 
seseorang. Hal ini sependapat dengan Reksohadiprojo (1988:169) bahwa motivasi sebagai seseuatu yang menyebakan, menyalurkan serta melestarikan perilaku seseorang.

\section{KAJIAN LITERATUR}

Motivasi kerja adalah daya pendorong yang mengakibatkanseseorang atau organisasi mau dan rela untuk mengerahkankemampuannya dalam bentuk keahlian atau keterampilan, tenaga dan juga waktunya untuk menyelenggarakan berbagai kegiatan yang menjadi tanggung jawabnya dan menunaikan kewajibanna dalam rangka pencapaian tujuan perusahaan.

Motivasi terbentuk dari sikap (attitude) seorang pegawai dalam menghadapi situasi (situation) kerja. Motivasi merupakan kondisi yang menggerakan diri pegawai yang terarah untuk mencapai tujuan organisasi (tujuan kerja). Sikap mental merupakan kondisi yang mendorong diri pegawai untuk berusaha mencapai prestasi kerja secara maksimal. Sikap mental seorang pegawai harus siap secara psikofisik (siap mental, fisik, tujuan dan situasi). Artinya, seorang pegawai harus

mampu secara mental, mampu secara fisik, memahami tujuan utama, dan target kerja yang akan dicapai serta mampu memanfaatkan dan menciptakan situasi kerja.

Teori Abraham Maslow menyatakan pada suatu hirarki kebutuhan manusia yang bertingkat. Hirarki kebutuhan manusia menurut Maslow adalah

\section{Phisiological Needs}

Kebutuha yang paling mendasar pada manusia dimanivestasikan ke dalam tiga hal yaitu sandang, pangan, papan. Kebutuhan ini merupakan kebutuhan primer untuk memenuhi kebutuhan psikologis dan biologis

2. Safety Needs

Setelah kebutuhan primer terpenuhi manusia akan mencari kebutuhan yang lain yaitu kebutuhan akan perlindungan dari bahaya ancaman (bencana, penyakit, perang, kemiskinan, kelaparan, sakit, dan lain- lain) kondisi kerja serta kebutuhan akan perlakuan yang adil dan jaminan hari tua.

3. Social Needs

Kebutuhan sosial yang meliputi rasa diterima orang lain, kebutuhan untuk maju, tidak gagal dan kebutuhan rasa ikut serta

4. Esteem Needs

Merupakan kebutuhan manusia akan penghargaan, prestasi dan pengakuan dari pihak lain.

5. Self Actualization

Kebutuhan dari kepuasan diri yang merupakan realisasi secara menyeluruh dari potensi seseorang
Penilaian pelaksanaan pekerjaan perlu dilakukan secara formal berdasarkan serangkaian kriteria yang ditetapkan secara rasional serta diterpan secara obyektif serta didokumentasikan secara sistematik. Hal inni perlu ditetapkan karena tidak sedikit manajer yang beranggapan bahwa pelaksanaan penilaian prestasi kerja secara formal oleh bagian - bagian personalia sebenarnya tidak diperlukan dan bahkan dipandang sebagai gangguan terhadap pelaksanaan kegiatan operasional.

Menurut Ilyas (2001) penilaian prestasi kerja adalah proses yang dilakukan untuk menilai pelaksanaan pekerjaan atau unjuk kerja seorang personil dan untuk memberikan umpan balik bagi kesesuaian dan peningkatan kerja tim. Saydam (2005) mengemukakan bahwa pengertian penilaian prestasi kerja adalah merupakan proses kegiatan yang dilakukan untuk mengevaluasi

tingkat pelaksanaan pekerjaan atau unjuk kerja seorang karyawan. Moekijat (1995) mengemukakan bahwa pengertian penilaian prestasi kerja adalah suatu proses yang dapat digunakan oleh organisasi untuk menilai pelaksanaan pekerjaan pegawai. Yuli (2005) mengemukakan bahwa pengertian penilaian prestasi kerja adalah proses penilaian prestasi kerja karyawan yang dilakukan olehorganisasi te rhadap karyawannya secara sistematik dan formal berdasarkan pekerjaan yang ditugaskan kepadanya.

Menurut Hasibuan (1990), tujuan penilaian prestasi kerja karyawan

adalah :

a. Sebagai dasar dalam pe ngambilan keputusan yang digunakan untuk promosi, demosi, pemberhentian dan penetapan besarnya balas jasa.

b. Untuk mengatur prestasi kerja sejauhmana karyawan bisa sukses dalampekerjaannya.

c. Sebagai dasar untuk mengevaluasi efektivitas seluruh kegiatan diperusahaan.

d. Sebagai dasar untuk mengevaluasi program latihan dan keefektivan jadwal kerja, metode kerja, struktur organisasi, gaya kepengawasan,kondisi kerja dan peralatan kerja.

e. Sebagai indikator untuk menentukan kebutuhan akan latihan bagi karyawan yang berada dalam organisasi.

f. Sebagai alat untuk meningkatkan motivasi kerja karyawan sehinggadicapai tujuan untuk mendapatkan performance kerja yang baik.

g. Sebagai alat untuk mendorong atau membiasakan para (supervisor,manager, administrator) untuk mengobservasi perilaku bawahan (subordinate) supaya diketahui minat dan kebutuhan-kebutuhan bawahannya.

h. Sebagai alat untuk bisa melihat kekurangan atau kelemahan-kelemahan dimasa lampau 
dan meningkatkan kemampuan-kemampuan karyawan selanjutnya.

i. Sebagai kriteria didalam menentukan seleksi dan penempatan karyawan.

j. Sebagai alat untuk mengidentifikasi kelemahan-kelemahan personil dan dengan demikian bisa sebagai bahan pertimbangan agar bisa diikutsertakan dalam program latihan kerja tambahan.

k. Sebagai alat untuk memperbaiki atau mengembangkan kecakapakaryawan.

Berdasarkan penjelasan diatas, maka konsep/kerangka pikir dalam penelitian adalah sebagai berikut:

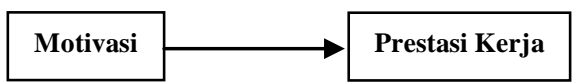

Model Hipotesis

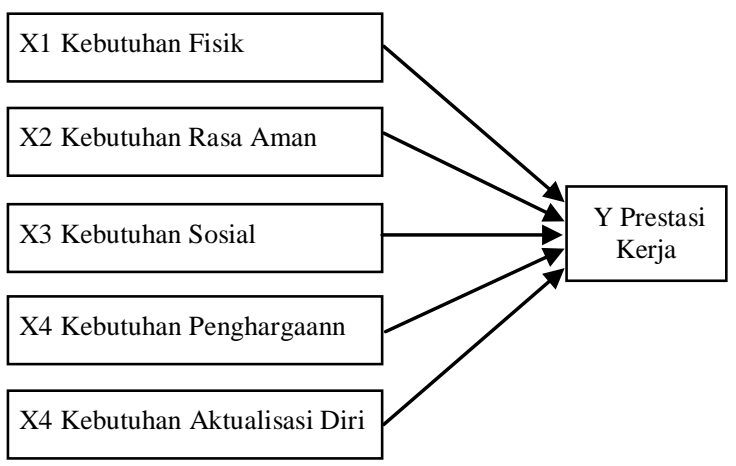

Berdasarkan model konseptual pada Gambar, maka hipotesis dalam penelitian ini adalah sebagai berikut:

H1 = diduga motivasi berpengaruh secara simultan terhadap prestasi kerja

H2 = Diduga variabel motivasi berpengaruh secara parsiali terhadap prestasi kerja

Teknik Pengumpulan data dengan pengamatan (wawancara atau koesioner) (Sugiyono, 2015) dalam penelitian ini adalah untuk memperoleh data primer yang di dapat langsung dari koesioner. Populasi adalah wilayah generalisasi yang terdiri atas : obyek/subyek yang mempunyai kuantitas dan karakteristik tertentu yang ditetapkan oleh peneliti untuk dipelajari dan ditarik kesimpulannya (Sugiyono, 2015).

Populasi dalam penelitian ini adalah Karyawan PT INHUTANI II Kota Baru.

Sampel adalah sebagian dari jumlah dan karakteristik yang dijadikan objek penelitian (sugiyono, 2016 : 148). Teknik pengambilan sample menggunakan nonprobability sampling. Dalam penelitan ini menggunakan Purposive sampling. Perposive sampling adalah teknik penentuan sampel dengan pertimbangan tertentu (Sugiyono, 2016 : 156). Karen ajumlah populasi yang banyak tidak mungkin diteliti semua, mengingat keterbatasan waktu, tenaga dan biaya maka penelitian yang dilakukan hanya meneliti dari sebagian jumlah populasi atau disebut sampel. Untuk menetukan jumlah sampel dengan rumus sebagai berikut

$\mathbf{n}=\frac{\mathrm{N}}{\mathrm{N}(\mathrm{d})^{2}+1}$

Keterangan : $\mathrm{n}=$ Jumlah seluruh sampel

$\mathrm{N}=$ ukuran populasi

$\mathrm{d}=$ tingkat pressisi $(5 \%)$

jumlah pelanggan yang datang 80 (delapan puluh) orang, sehingga jumlah sampel adalah

$$
\begin{aligned}
n & =\frac{80}{80(0,05)^{2}+1} \\
& =67 \text { orang }
\end{aligned}
$$

Jadi, sampel penelitian ini sebanyak 67 orang.

Instrument penelitian yang digunakan dalam penelitian ini adalah untuk memperoleh data primer artinya data yang didapat langsung dari responden berupa kuesioner. Bentuk kuesioner yang digunakan adalah kuesioner tertutup yaitu berisi pertanyaan yang disertai dengan pilihan jawaban. Skala pengukuran yang digunakan dalam penelitian ini adalah skala likert.

\section{HASIL PENELITIAN DAN PEMBAHASAN}

\section{Hasil Uji Validitas}

Uji validitas adalah suatu data dapat dipercaya kebenarannya sesuai dengan kenyataan. Menurut Sugiyono, 2009 bahwa valid berarti instrumen tersebut dapat digunakan untuk mengukur apa yang seharusnya diukur. Sebuah item pertanyaan dianggap valid apabila koefesien korelasi product moment pearson dimana r-hitung lebih besar dari r-tabel dengan tingkat signifikan $1 \%$. Pada penelitian ini uji validitas menggunakan uji validitas pearson Corellation. Berikut hasil uji validitas dengan menggunakan SPSS 23 For windows :

Tabel 1 Variabel X1,X2, X3, X4, X5, Y

\begin{tabular}{ccccc}
\hline variabel & Pertanyaan & $\begin{array}{c}\mathrm{r}- \\
\text { hitung }\end{array}$ & $\begin{array}{c}\mathrm{r}- \\
\text { tabel }\end{array}$ & Keterangan \\
\hline & $\mathrm{X} 1.1$ & 0,642 & 0,317 & Valid \\
\cline { 2 - 5 } & $\mathrm{X} 1.2$ & 0,758 & 0,317 & Valid \\
\cline { 2 - 5 } $\begin{array}{c}\text { Kebutuhan } \\
\text { fisik }\end{array}$ & $\mathrm{X} 1.3$ & 0,724 & 0,317 & Valid \\
\cline { 2 - 5 } & $\mathrm{X} 1.4$ & 0,679 & 0,317 & Valid \\
\hline
\end{tabular}




\begin{tabular}{|c|c|c|c|c|}
\hline variabel & Pertanyaan & $\begin{array}{c}\mathrm{r}- \\
\text { hitung }\end{array}$ & $\begin{array}{c}\mathrm{r}- \\
\text { tabel }\end{array}$ & Keterangan \\
\hline \multirow{3}{*}{$\begin{array}{c}\text { Kebutuhan } \\
\text { rasa aman }\end{array}$} & $\mathrm{X} 2.1$ & 0,740 & 0,317 & Valid \\
\hline & $\mathrm{X} 2.2$ & 0,794 & 0,317 & Valid \\
\hline & $\mathrm{X} 2.3$ & 0,725 & 0,317 & Valid \\
\hline \multirow{3}{*}{$\begin{array}{l}\text { Kebutuhan } \\
\text { sosial }\end{array}$} & X3.1 & 0,819 & 0,317 & Valid \\
\hline & X3.2 & 0,713 & 0,317 & Valid \\
\hline & X3.3 & 0,752 & 0,317 & Valid \\
\hline \multirow{3}{*}{$\begin{array}{l}\text { Kebutuhan } \\
\text { penghargaan }\end{array}$} & $\mathrm{X} 4.1$ & 0,847 & 0,317 & Valid \\
\hline & $\mathrm{X} 4.2$ & 0,802 & 0,317 & Valid \\
\hline & $\mathrm{X} 4.3$ & 0,741 & 0,317 & Valid \\
\hline \multirow{2}{*}{$\begin{array}{l}\text { Kebutuhan } \\
\text { aktualisasi } \\
\text { diri }\end{array}$} & $\mathrm{X} 5.1$ & 0,740 & 0,317 & Valid \\
\hline & $\mathrm{X} 5.2$ & 0,762 & 0,317 & Valid \\
\hline \multirow{2}{*}{ Prestasi kerja } & Y1 & 0,894 & 0,317 & Valid \\
\hline & Y2 & 0,885 & 0,317 & Valid \\
\hline
\end{tabular}

\section{Uji Reliabelitas}

Uji reliabilitas pada umumnya diukur dengan menggunakan Cronbach's Alpha dari instrumen suatu variabel. Instrumen yang dipakai deealam variabel dikatakan andal atau reliabel apabila memiliki Cronbach's Alpha dari 0.6.

Berikut hasil uji reliabilitas dengan menggunakan SPSS 23 for windows Tabel 2 Hasil Uji Reliabilitas Instrumen Data

\begin{tabular}{ccc}
\hline Variabel & $\begin{array}{c}\text { Cronbach's } \\
\text { Alpha }\end{array}$ & Keterangan \\
\hline Kebutuhan fisik & 0,656 & Reliabel \\
\hline $\begin{array}{c}\text { Kebutuhan rasa } \\
\text { aman }\end{array}$ & 0,621 & Reliabel \\
\hline $\begin{array}{c}\text { Kebutuhan sosial } \\
\text { Kebutuhan } \\
\text { penhargaan }\end{array}$ & 0,643 & Reliabel \\
\hline $\begin{array}{c}\text { Kebutauhan } \\
\text { aktualisasi diri }\end{array}$ & 0,712 & Reliabel \\
\hline Prestasi kerja & 0,651 & Reliabel \\
\hline
\end{tabular}

\section{Uji Asumsi Klasik}

a. Hasil Uji Normalitas

Hasil perhitungan normalitas data dengan SPSS 23 pada lampiran menunjukkan bahwa penyebaran plot berada disekitar dan sepanjang garis, dengan demikian menunjukkan bahwa data - data variabel peneltian berdistribusi normal.
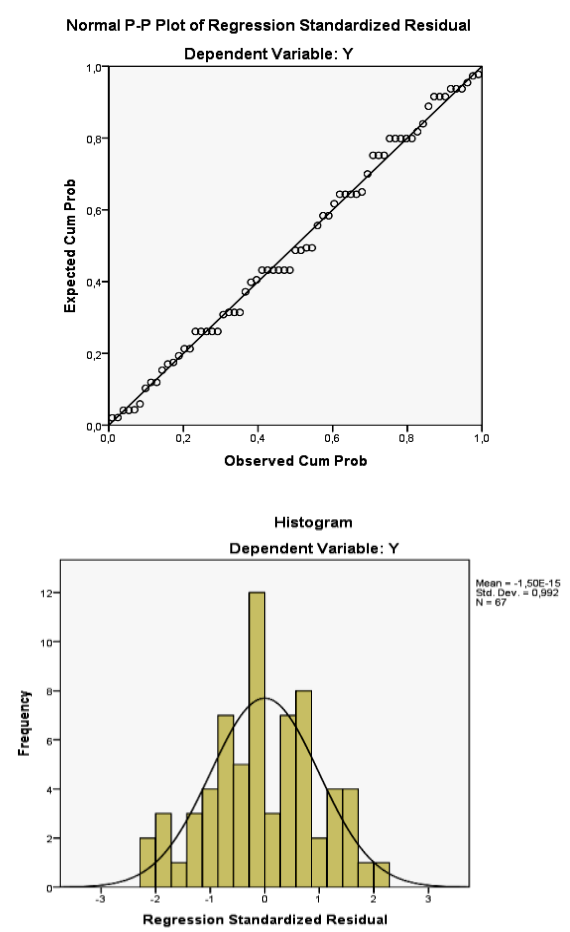

b. Uji Multikolinieritas

Berdasarkan hasil komputasi dengan menggunakan bantuan program SPSS 23 For windows maka dapat nilai Tolerance dan VIP pada tabel dibawah ini :

Hasil Uji Multikolinieritas dengan tolerance dan VIP

\begin{tabular}{ccc}
\hline \multirow{2}{*}{ Variabel } & \multicolumn{2}{c}{ Collinearity Statistics } \\
\cline { 2 - 3 } & Tolerance & VIF \\
\hline Kebutuhan fisik & 0,729 & 1,371 \\
\hline $\begin{array}{c}\text { Kebutuhan rasa } \\
\text { aman }\end{array}$ & 0,756 & 1,323 \\
\hline $\begin{array}{c}\text { Kebutuhan } \\
\text { sosial }\end{array}$ & 0,742 & 1,347 \\
\hline $\begin{array}{c}\text { Kebutuhan } \\
\text { penghargaan }\end{array}$ & 0,781 & 1,281 \\
\hline $\begin{array}{c}\text { Kebutuhan } \\
\text { aktualisasi diri }\end{array}$ & 0,856 & 1,156 \\
\hline Berdasarkan
\end{tabular}

Berdasarkan tabel di atas menunjukkan bahwa model regresai dalam penelitian ini bebas dari multikolinieritas, karena niai tolerance lebih dari 0,10 dan nila VIF kurang dari 10

c. Hasil Uji Keterkoskedasitas

Berdasarkan hasil komputasi menggunakan bantuan SPSS 23 For windows maka hubungan antara nilai variabel yang dipredeksi dengan residualnya adalah : 


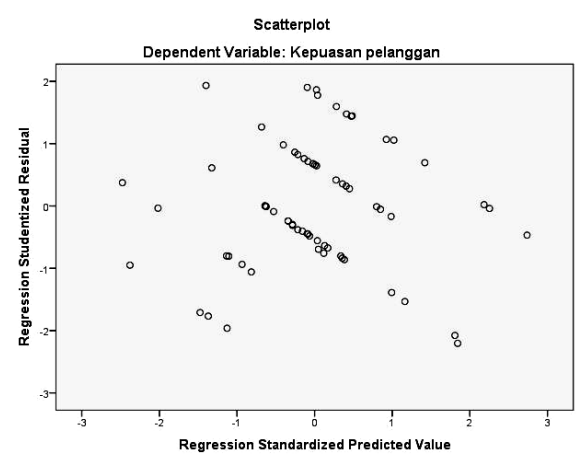

\section{Analisis Korelasi}

Analisis korelasi pearson atau dikenal dengan korelasi product moment adalah analisis untuk mengukur keeratan hubungan secara linier antara dua variabel yang mempunyai distribusi data nominal. Data yang digunakan adalah tipe interval atau rasio. Dasar pengambilan keputusan jika nilai signifikansi < 0,01, maka berkorelasi dan jika nilai signifakansi $>0,01$ maka tidak berkorelasi. Selanjutnya untuk mengetahui kuat lemahnya hubungan korelasi dari dua variabel dapat dikategorikan sebagai berikut (Sugiyono, 2007).

- Nilai pearson corelation 0,00 sd $0,20=$ tidak ada korelasi

- Nilai pearson corelation 0,21 sd $0,40=$ korelasi lemah

- Nilai pearson corelation 0,41 sd $0,60=$ korelasi sedang

- Nilai pearson corelation 0,61 sd $0,80=$ korelasi kuat

- Nilai pearson corelation 0,81 sd $1,0=$ sangat kuat

Berikut hasil analisis korelasi product moment dengan menggunakan program spss 23 for windows pada tabel dibawah :

\begin{tabular}{cccc}
\multicolumn{3}{c}{ Hasil analisis corelation product moment } \\
\hline No & Variabel & \multicolumn{2}{c}{ Prestasi kerja (Y) } \\
\cline { 3 - 4 } & $\begin{array}{c}\text { Pearson } \\
\text { corelation }\end{array}$ & $\begin{array}{c}\text { Sig. 2- } \\
\text { tailed }\end{array}$ \\
\hline 1 & $\begin{array}{c}\text { Kebutuhan fisik } \\
(\mathrm{X} 1)\end{array}$ & 0,464 & 0,000 \\
\hline 2 & $\begin{array}{c}\text { Kebutuhan rasa } \\
\text { aman (X2) }\end{array}$ & 0,497 & 0,000 \\
\hline 3 & $\begin{array}{c}\text { Kebutuhan sosial } \\
(\mathrm{X} 3)\end{array}$ & 0,471 & 0,000 \\
\hline 4 & $\begin{array}{c}\text { Kebutuhan } \\
\text { penghargaan (X4) }\end{array}$ & 0,461 & 0,000 \\
\hline 5 & $\begin{array}{c}\text { Kebutuhan } \\
\text { aktualiasasi (X5) }\end{array}$ & 0.426 & 0,000 \\
\hline
\end{tabular}

Korelasi
Membandingkan person corelation dengan $\mathrm{r}$ tabel

- $\quad$ Pearson corelation $>r$-tabel $=$ berpengaruh

- Pearson corelatio $<$ r-tabel $=$ tidak berhubungan

Diketahui person corelation 0,464 dengan r-tabel 0,317 maka terdapat pengaruh antara kebutuhan fisik dengan prestasi kerja.

Diketahui person corelation 0,497 dengan r-tabel 0,317 maka terdapat pengaruh antara kebutuhan rasa aman dengan prestasi kerja.

Diketahui person corelation 0,471 dengan r-tabel 0,317 maka terdapat pengaruh antara kebutuhan sosial dengan prestasi kerja.

Diketahui person corelation 0,461 dengan r-tabel 0,317 maka terdapat pengaruh antara Kebutuhan penghargaan dengan prestasi kerja

Diketahui person corelation 0,426 dengan r-tabel 0,317 maka terdapat pengaruh antara kebutuhan aktualisasi dengan prestasi kerja.

Disimpulkan kebutuhan fisik, kebutuhan rasa aman, kebutuhan sosial, kebutuhan penghargaan, kebbutuhan aktualiasi memiliki hubungan secara positif dengan derajat hubungan korelasi yang sedang terhadap prestasi kerja (Y). Karena semua variabel saling berhubungan masing - masing memiliki koefisien korelasi antara 0,41 sd 0,60 yang termasuk dalam kategori sedang dan disertai dengan signifikasi (sig.) $0,000<$ 0,01 .

\section{PENUTUP}

\section{Kesimpulan}

Diketahui bahwa variabel motivasi berpengaruh secara signifikan dan positif terhadap prestasi kerja karyawan PT INHUTANI II Kota Baru Kalimantan Selatan.

Motivasi yang terdiri dari kebutuhan fisik, kebutuhan rasa aman, kebutuhan sosial, kebutuhan penghargaan, kebutuhan aktualisasi diri secara simultan berpengaruh erat corelation coefficient mendekati 1 terhadap prestasi kerjakaryawan PT INHUTANI II Kota Baru Kalimantan Selatan.

kebutuhan fisik, kebutuhan rasa aman, kebutuhan sosial, kebutuhan penghargaan, kebbutuhan aktualiasi memiliki hubungan secara positif dengan derajat hubungan korelasi yang sedang terhadap prestasi kerja (Y). Karena semua variabel saling berhubungan masing - masing memiliki koefisien korelasi antara 0,41 sd 0,60 yang termasuk dalam kategori sedang dan disertai dengan signifikasi (sig.) $0,000<0,01$

Perusahaan harus member kesempatan pada karyawan untuk berkreatifitas sendiri karena dalam 
hal ini kreatifitas sangat penting pengaruhnya terhadap prestasi kerja karyawan dan lebih meningkatkan prestasi kerja karyawan dengan memberikan insentif dan pengharaan pada karyawan yang berprestasi serta menjamin karir karyawan

\section{DAFTAR PUSTAKA}

Arep Ishak dan Tanjung hendri 2003, Manajemen motivasi, Penerbit Gramedia Widiasarana Indonesia, Jakarta

Arikunto, Suharmisi. 2006. Prosedur Penelitian. BinaAksara, Jakarta.

Dessler, Gary, 2007, Manajemen Sumber Daya Manusia, Prentice Hall. Indonesia

Dharma, Agus 1986, Gaya Kepemimpinan Yang Efektif bagi Manajer. Bandung CV. Sinar baru
Gaol Jimmy, L 1992 Manajemen Kepegawaian. Cetakan pertama, Penerbit Karunika jakarta, Universitas Terbuka, jakarta

\section{Profil Penulis :}

Kumara Efrianti, SE., MM. Dosen Fakultas Ekonomi Universitas Islam Kalimantan Muhammad Arsyad Al Banjari

Email : kefrianti@gmail.com 